Ancyloxypha numitor. W. 5, 6, 7, $14^{8}$ Jun.; I. 5 Ag.

Ocytes metea. W. $23 \mathrm{My}^{2}$.

Atrytone conspicua. L. 17 ? Jl.

Atrytone zabulon. W. My. ${ }^{14}, 1^{8}, 3^{4}, 4^{2}, 6^{3}, 7^{4}, 8^{3}, 13^{9}, 19,20$ Jun.

Pamphila sassacus. W. $22 \mathrm{My} .4^{4}, 5^{8}, 6^{8}, 7^{2}, 8,13^{2}$ Jun.

Anthomaster leonardus. W. Jun.; 28 Ag.

Polites peckius. W. My., 1, 32, $7^{4}$ Jun.; B. 6-15 Jl.; L. 8, 10, 12 Ag.

Hedone aetna. B. $6^{2}, 8-15^{6} \mathrm{Jl}$.

Limochores mystic. W. $6,8,13^{4}, 14^{5}, 19^{6}, 25$ Jun., 150.

Limochores bimacula. B. $6^{5}, 8^{2} \mathrm{Jl}$.

Limochores taumas. W. My. ${ }^{9}, 3,5,6^{2}, 7^{2}, 13^{2}$ Jun.; B. 8 Jl.; L. Jl. and Ag.

Euphyes metacomet. B. 13,16 Jl.; L. $18^{2}, 19^{2}$ Jl., 3 Ag. ${ }^{2}$.

Lerema hianna. W. 4, 6, 7, 8, 1338, 19 Jun.

F. H. Sprague.

\title{
Westward Progress of Eristalis tenax, Linn.
}

Reading lately the interesting account of the American occurrence of this insect (Psyche, 1878, v. 2, p. 188), I was led to examine my Syrphidae, collected during the past five years.

I find that I have taken nine specimens of $\boldsymbol{E}$. tenax, now fully identified as such by Mr. Burgess' description and by comparison with five European instances. Of my local captures four are males and five females, and the dates are these: 1876, July 23, $q ; 1877$, Sept. 2 and 16, $\delta$ o , Sept. 23, $q$, Oct. $14, \delta$ \& $\%$, Oct. $24, q ; 1878$, July 23, $q$. All these were taken within three miles of Galena, Illinois. Thos. E. Bean.

Galena, Ill.

\section{The Ovipositor of Amblychila.}

The eighth abdominal segment of Amblychila is withdrawn within the abdomen. Its ventral arc in the female has a deep median slit and extends beyond the dorsal arc. Enclosed within this segment, and extending as far as its ventral arc, there is apparent a large plate cleft into three pieces, which probably represent the dorsal and pleural pieces of a ninth abdominal segment. Underneath these are a pair of large and stout chitinous processes having an upward curve. These somewhat resemble the processes which form the ovipositor of Acrididae, and probably serve likewise to bore into the ground 
for the purpose of depositing the eggs. The position in which the eggs are laid appears to be similar to that of the Acrididae, for Mr. Williston stated (Can. Entom., Sept.1877, v. 9, p. 164) that " the eggs are deposited near the surface of the ground in groups of from one to two dozen."

W. H. Patton.

\section{BIBLIOGRAPHICAL RECORD.}

(Continued from page 256.)

The date of publication, here given in brackets [ ], marks the time at which the work was received by the Editor, unless an earlier date of publication is known to him. An asterisk * before a title is the Recorder's certificate of accuracy of quotation. Corrections of errors and notices of omissions are solicited. - B : Pickman Mann.

Nos. 1215 to 1266 are from Can. entom., 1877, v. 9.

* 1215. Grote, A: Radcliffe. New species of lepidoptera. (Can. entom., 1877, v. 9, p. 156-158.)

Describes Scopelosoma tristigmata, Tarache abdominalis, Geometra rectaria, $=3$ n. spp. [Aug., 1877.]

* 1216. [Saunders, W:] Entomological Club of the American Association for the Advancement of Science. (Can. entom., 1877 , v. 9 , p. 158.)

Notification of the meeting of the Club, to be held at Nashville, Tenn., 28 Aug., 1877. [Aug., 1877.]

* 1217. Saunders, W: Clisiocampa sylvatica - The forest tent caterpillar. (Can. entom., 1877, v. 9, p. 158-159, fig. 6.)

Abundance of C. sylvatica near London, Ont., in 1877 ; habits, foodplants and ravages of the larvae ; figure of a larva. [Aug., 1877.]

* 1218. Denton, J: Mabbot. Papilio thoas. (Can. entom., 1877 , v. 9, p. 160.)

Eleven specimens caught near Amherstburg, Ont., 1 and 2 Aug., 1877. [Aug., 1877.]

* 1219. Saunders, W: Cisthene subjecta. (Can. entom., 1877 , v. 9 , p. 160 .)

Two specimens caught [? at London, Ont.,] on Asclepias in July. [Aug., 1877.]

* 1220. Bates, James Elwyn. Melitaea phaeton. (Can. entom., 1877 , v. 9 , p. 160.)

Abundance of $M$. phaeton, and occurrence of one Myrmeleon obsoletus and of one Psychomorpha epimenis at South Abington, Mass., in 1877. [Aug., 1877.] 

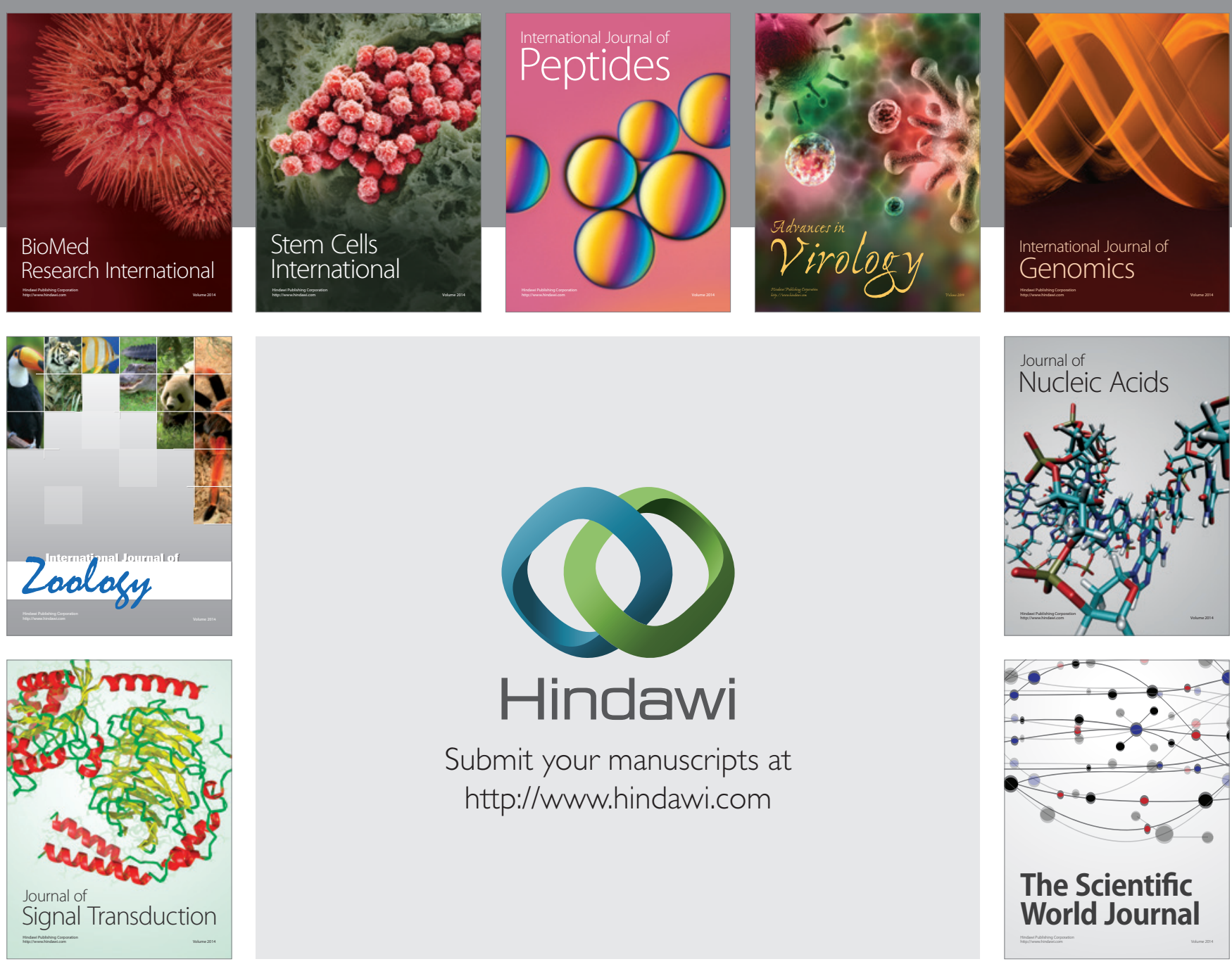

Submit your manuscripts at

http://www.hindawi.com
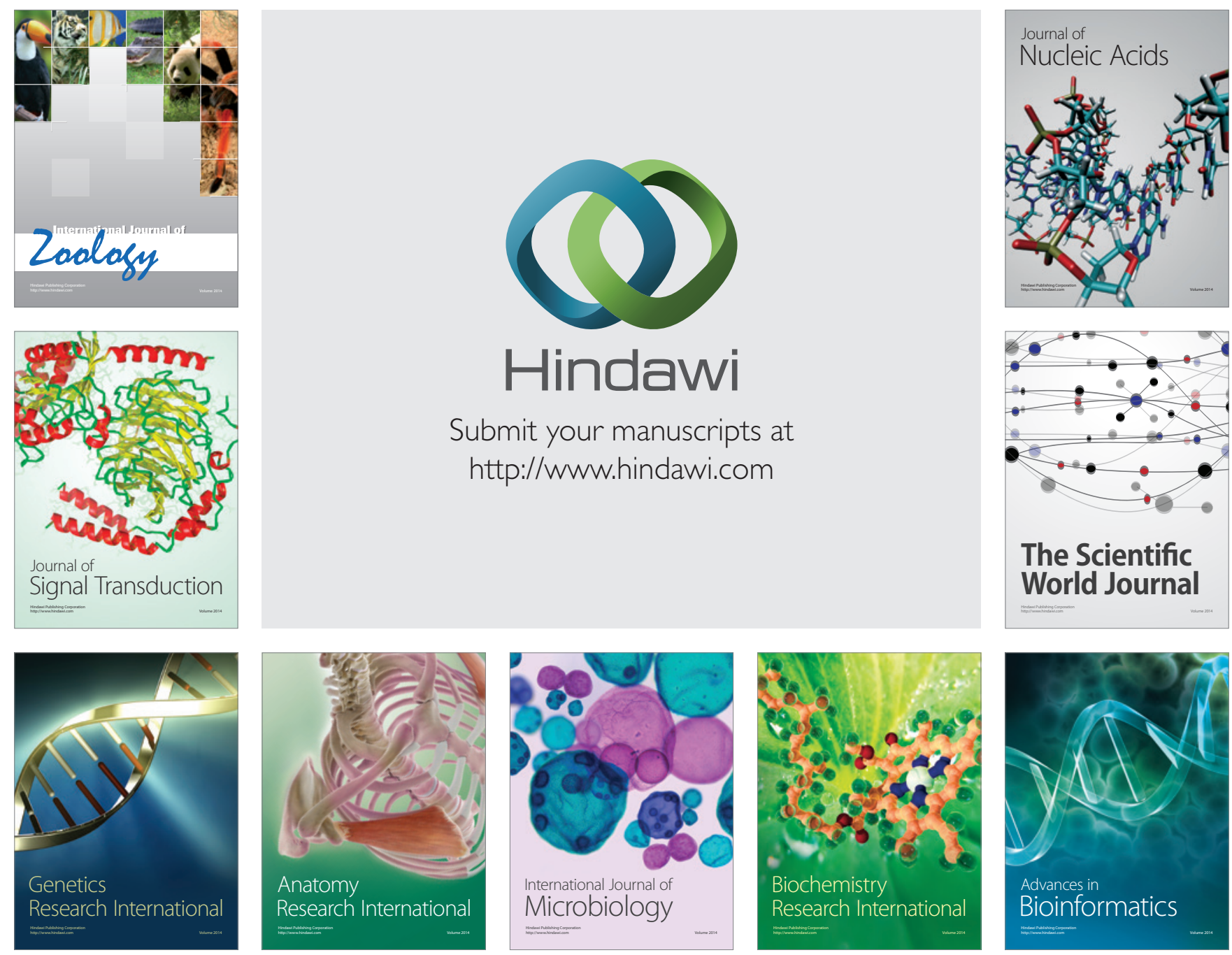

The Scientific World Journal
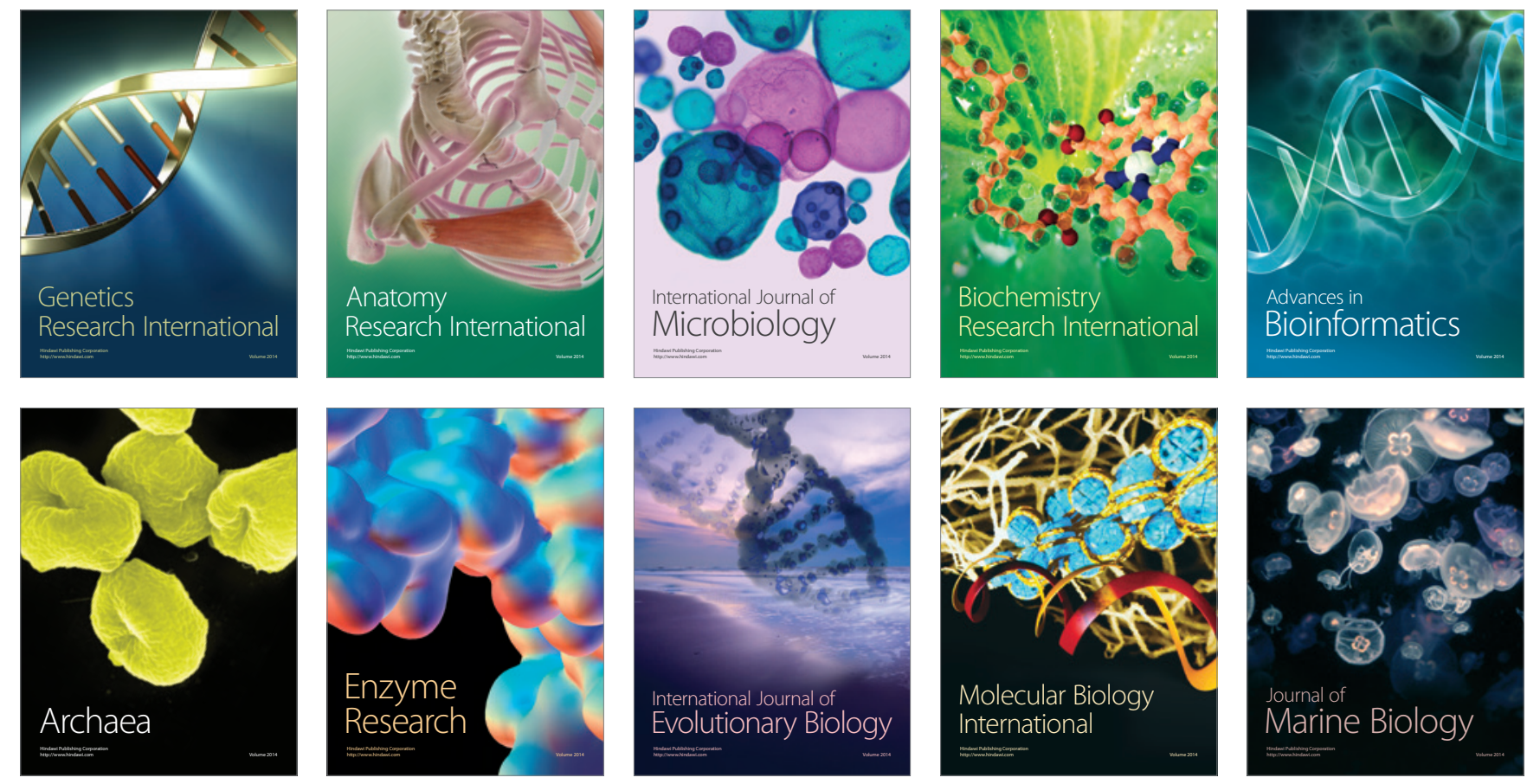